\title{
Performance Analysis of Non-Isolated DC-DC Buck Converter Using Resonant Approach
}

\author{
Kuldeep Jayaswal \\ Department of Electrical Engineering \\ Rajasthan Technical University \\ Kota, India \\ kuldeep12555@gmail.com
}

\author{
Dheeraj Kumar Palwalia \\ Department of Electrical Engineering \\ Rajasthan Technical University \\ Kota, India \\ dheerajpalwalia@gmail.com
}

\begin{abstract}
DC-DC converters preserve or control the output DC voltage. Due to parasitic constituents such as leakage capacitance of both diode and inductor, and transformer leakage inductance, DC-DC converters mostly operate on rigid switching conditions which result in high switching losses. These parasitic constituents affect the dc-dc converter's operational reliability, instigate electromagnetic interference issues and limit the converter's operation at higher frequency operations. In this paper, resonant or soft-switch approach has been employed to improve the operating performance and design-oriented principle investigations have been carried out for overcoming the issues of parasitic constituents in 24-12V DC-DC step-down (buck) converter. This paper divulges the analysis and Matlab Simulation results for $24-12 \mathrm{~V}$ buck converter based on resonant or soft-switching approach.
\end{abstract}

Keywords-operational reliability; DC-DC converter; resonant converter; Matlab simulation; step-down converter

\section{INTRODUCTION}

DC-DC conversion technologies are an important subject of research in the power engineering and drives area. These devices are electronic platforms used to customize DC electric voltage efficiently [1]. These converters are mostly used for changing the different voltage level [2-5]. Mainstream PWM converters do not work on soft-switch approach, they mostly operate on hard switching conditions. Semiconductor devices suffer from switching losses and electro-magnetic interference problems during switching-on and off which results in poor converter performance [5-6]. There are various factors which are accountable of switching loss like capacitance of both diode and switch [7-11]. This paper shows the softswitch/resonant approach based on null voltage switching operation for reduction of all uncertainties related to customary DC-DC buck converter.

\section{NON-ISOLATED DC-DC CONVERTER TOPOLOGIES AND RESONANT/SOFT-SWITCH APPROACH}

A. The Concept Behind the Requirment of Resonant Approach DC-DC semiconductor devices like BJT, MOSFET or IGBT work as a switch at required frequency $(f)$ [12]. The elementary circuit topologies of non-isolated dc-dc converters are shown in Figure 1 [13-19]. The voltage and current waveforms of the switch may have different shapes. As the voltage and current across the switch are not zero during switching times, there will be switching losses. Due to this, the switching frequency is bounded in pulse-width modulating converters. If the frequency is increased, then high electromagnetic interference problems will occur [2]. High stress will be on device during switching times due to high spikes in switch voltage and current. That's why such a switching results to low switching losses.

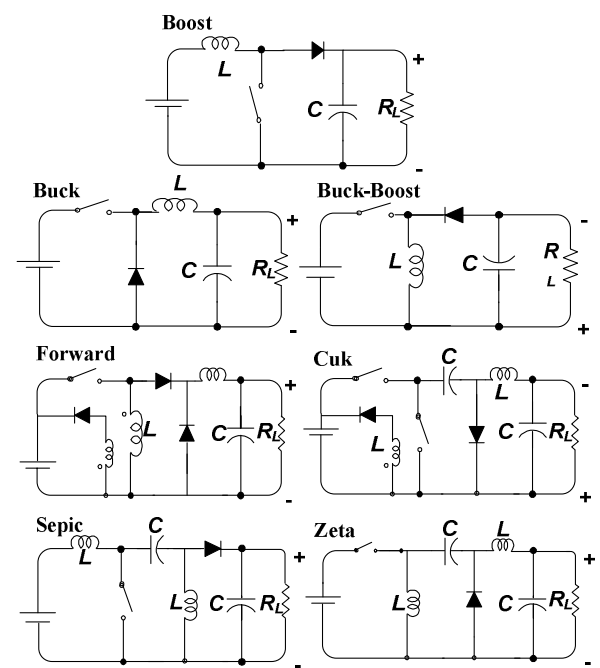

Fig. 1. Non-isolated DC-DC converter topologies without resonant/softswitch approach

In this paper, the buck non-isolated topology has been used as a principal platform to revamp performance and operational reliability of the converter. For this purpose, zero voltage switch operational approach has been used via appropriate placement of resonant switches. MOSFETs and IGBTs are mostly used as a switch in electronic conversions where at a particular time period they have to operate either in fully on or off condition. Being a current controlled device, MOSFETs are much faster in switching operation in comparison to BJT [8]. Thus, these devices are most eligible to work at higher switching frequencies. 


\section{B. Switch Configuration Concept for ZVS Approach}

Switching losses are related to the switching frequency $f_{S}$, and these losses limit the maximum switching frequency. The energy reserved in output capacitance $C_{o}$ of switch just before the transistor turns on is given as

$$
W_{C_{o}}=V_{o f f}^{2} C_{o} / 2
$$

where $V_{o f f}=$ transistor voltage during off-instant.

When the switch turns on, the energy imposed on the switch, causes transistor switching loss

$$
P_{S w(F E T)}=V_{o f f}^{2} C_{o} f_{s} / 2
$$

In this approach, a special switch configuration has been used which is made up with combinations of two different resonant elements with an anti-parallel diode. Figure 2 shows the switch configuration for resonant or smooth switching [1419]. Here a capacitor is coupled in counterpart with SW and resonant inductor in series. In this paper, resonant or zero voltage, switch operational approach has been used for the analysis of 24-12V DC-DC step-down converter. According to this when the switch is on, the voltage at the switch becomes zero, and that's why the energy reserved in the output capacitance of switch is null during turn this time. Hence, the switching on losses becomes zero, which provides smooth efficient operation at high frequencies and results in the reduction in the amplitude of the converters. During this period, the above mentioned switch configuration plays a crucial role. In this, the resonant capacitor will resonate to null voltage before SW is turned-on. On the other hand, when the switch is turned-off, a little time is required to charge the resonant capacitor and hence the voltage over the SW is not increased abruptly. So, there is a very small overlapping between the SW current and voltage. So, the zero voltage switch operation is achieved. The main idea behind this approach is the fact that these soft-switch converter topologies absorb different parasitic components, like transformer's leakage inductance, output capacitance of both transistor and diode. Figure 3, exhibits the proposed topology for non-isolated buck (step-down) converter based on resonant technique. Initially the switch remains in off situation during this instant current across switch is null but the voltage is not.

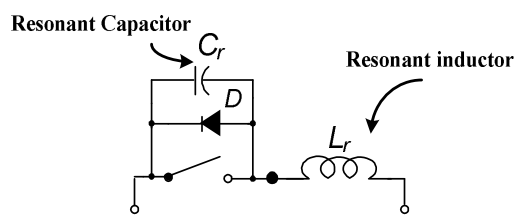

Fig. 2. ZVS approach based on resonant switch configuration

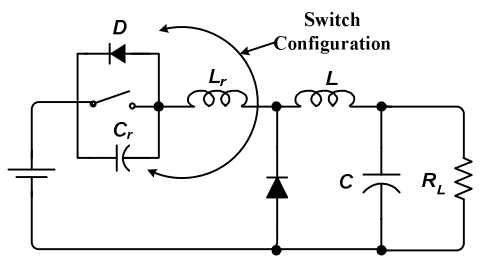

Fig. 3. Topology for non-isolated buck converter based on zero voltage switch/resonant approach
During the switch-on, the voltage is forced to be zero and the current is a little-bit delayed so that it will start to lift after the zero voltage as shown in Figure 4(b). In zero current switch approach, a switch is off during zero current. The voltage through it might be zero but the current across the device is not. Voltage is granted to lift after current becomes zero as illustrated in Figure 4(c).

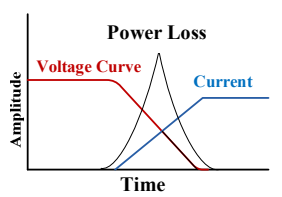

(a)

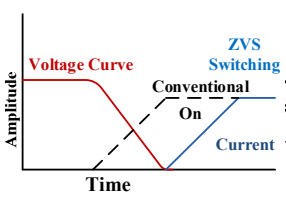

(b)

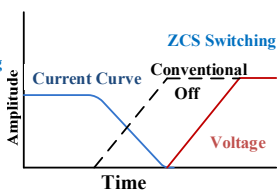

(c)
Fig. 4. (a) Firm-switching converter incident, (b) zero or null Voltage switching case, (c) zero or null current switching case

\section{ANALYSIS OF DC-DC BUCK CONVERTER WITH AND WITHOUT SOFT SWITCH APPROACH}

Figure 5 shows the conventional buck or step-down converter without resonant or soft switch approach, which is a cheap electronic device used to obtain reduced voltage.

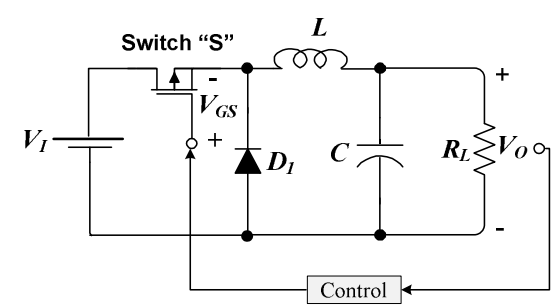

Fig. 5. DC-DC buck converter topology without resonant or soft switch approach

The switch operation is regulated by a modulator and turned-on and off at duty ratio "D" and at required switching frequency $f_{s}=1 / T$. Closed loop control has been used for stable operation:

$$
T D=t_{\text {on }} \Rightarrow t_{\text {on }} /\left(t_{\text {on }}+t_{\text {off }}\right)=t_{\text {on }} f_{s}
$$

The operational strategy consists of two stages. At $t=0$, the switch is in ON state and the diode is in OFF state because $V_{D}$ $=-V_{I}$. Further current across the inductor increases continuously due to voltage difference $V_{L}=V_{\Gamma} V_{O}$. At this time the current through the inductor and switch are both equal and energy is delivered to energy storage elements. In the second stage, at $t=D T$, the switch is in OFF state by gate driver, but during this time the inductor still has the previously stored current which turns the diode ON. During this instant, the voltage over the inductor is given as $\left(-V_{O}\right)$ and the voltage over the switch is given as $\left(V_{I}\right)$. That's why $\mathrm{I}_{\mathrm{L}}$ decreases continuously with a slope of $\left(-V_{O}\right) / L$. Input voltage is unplugged from the circuit and doesn't transfer any energy to the storage elements. The average output voltage in the buck converter is given by (4), which does not depend on load [6].

$$
V_{O} / V_{I}=D \Rightarrow V_{O}=V_{I} D
$$

The buck converter circuit based on the proposed approach is shown in Figure 8. 

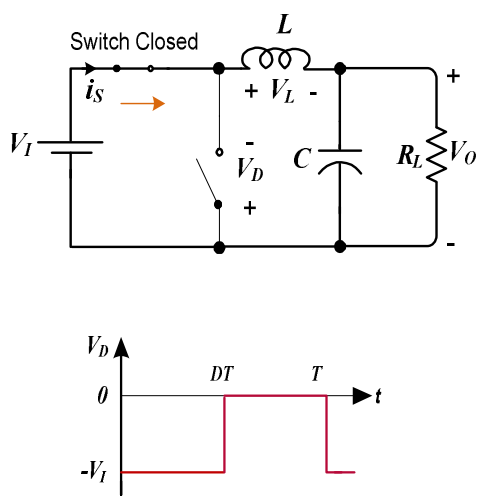

Fig. 6. Circuit state \& waveform for time interval $0<t \leq D T$
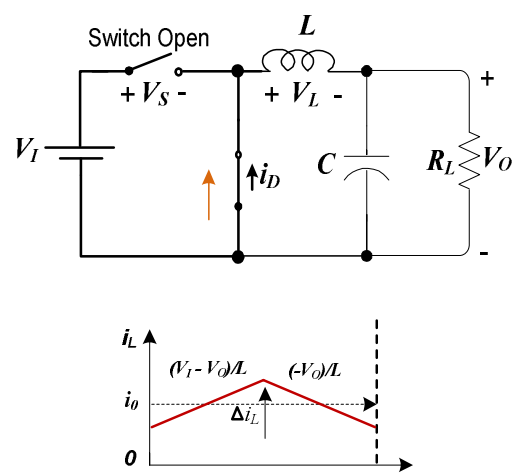

Fig. 7. Circuit state for time interval $D T<t \leq T$

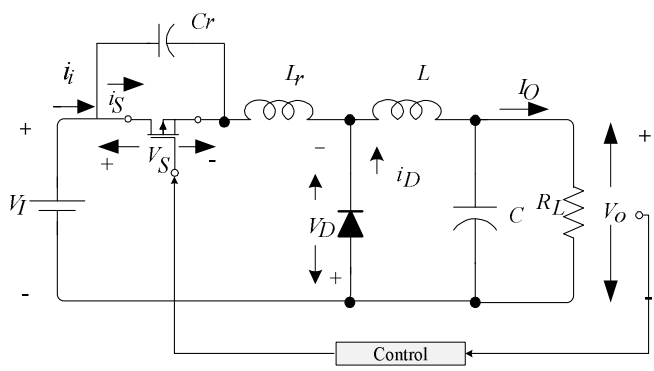

Fig. 8. Buck topology based on resonant approach

The current through the inductor $L$ remains somewhat constant so energy storage element is modelled as current sink, $I_{O}$. Table II, shows the analysis and operational process under four time segments, zero to $t_{1}, t_{1}$ to $t_{2}, t_{2}$ to $t_{3}$ and finally $t_{3}$ to $T$. For simulating dc-dc converter with and without resonant approach, complete mathematical analysis has been done for the design of a $24 \mathrm{~V}-12 \mathrm{~V}$ converter through different parametric equations. The converter based on the proposed approach has been analyzed through parametric equations for $24 \mathrm{~V}$ input and $12 \mathrm{~V}$ output for $100 \mathrm{KHz}$ and $1 \mathrm{MHz}$. By considering the different level of currents, loss calculations have been made for both types of converter and final remarks have been obtained which are depicted in Figure15 that shows the reliable or efficient performance of the converter.
TABLE I. PARAMETERIC EQUATIONS

\begin{tabular}{|c|c|}
\hline Parameters Used & Expressions \\
\hline Transfer function for DC voltage & $M_{V D C} \equiv V_{O} / V_{I}=1-\left(\frac{0.90}{f_{O}}\right) f_{S}$ \\
\hline Characteristics impedance $\left(\mathrm{Z}_{0}\right)$ & $\sqrt{L_{r} / C_{r}}$ or $(\omega)_{0}^{2}=\left(1 / L_{r} C_{r}\right)$ \\
\hline Max. current across switch from 0 to $D T$ & $I_{s m}=\left(\Delta i_{L}\right) / 2+i_{O}$ \\
\hline Quality factor $(Q)$ & $R_{L} / L_{r} \omega_{o}$ \\
\hline Resonant frequency ' $\mathrm{f}_{0}$ ' & $0.909^{*} f_{S} /(1-\mathrm{D})$ or $f_{S} / f_{n}$ \\
\hline Device stress for ' $\mathrm{S}$ ' and ' $\mathrm{D}$ ' & $\left(V_{s \max }\right)=2 V_{I} \& I_{s \max }=I_{0}$ \\
& $I_{D \max }=2 I_{0} \&$ \\
\hline Calculation of inductor's value $L r$ & $V_{D \max }=V_{I} / V_{O}=1 / D$ \\
\hline Calculation of capacitor's value $C r$ & $R_{L} / Q \omega_{o}$. \\
\hline Max. voltage across switch $V_{s m}$ & $Q / R_{L} \omega_{o}$. \\
\hline
\end{tabular}

\section{SimULATION RESULTS}

A. Without Resonant/Soft-Switch Approach

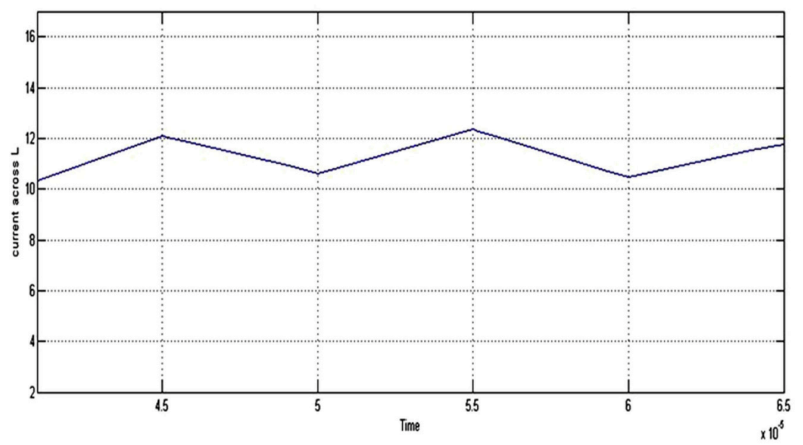

Fig. 9. Current across inductor

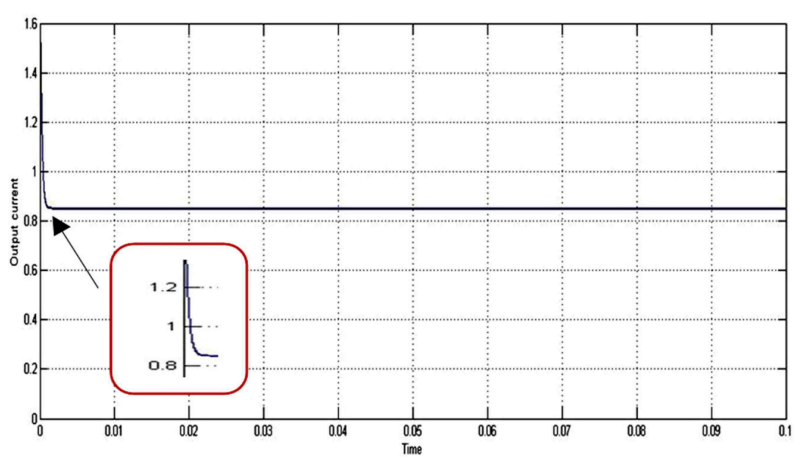

Fig. 10. Output current of buck converter (current versus time)

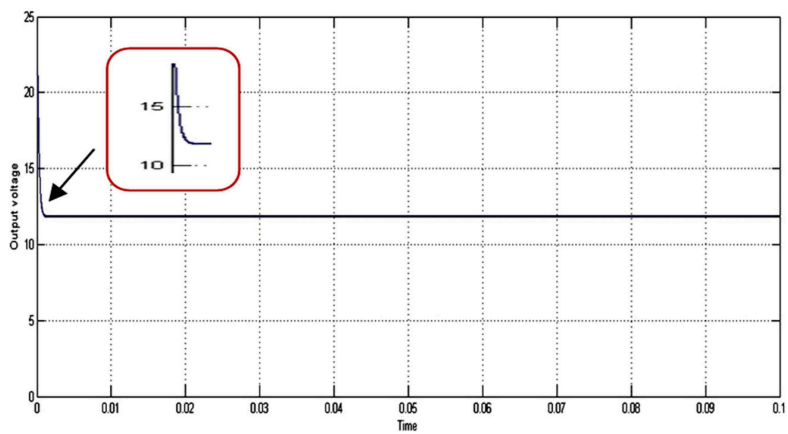

Fig. 11. Output voltage (12V) of buck converter (voltage versus time) 
TABLE II. OPERATIONAL PROCESS FOR NON-ISOLATED DC-DC BUCK CONVERTER USING RESONANT OR SOFT-SWITCH APPROACH

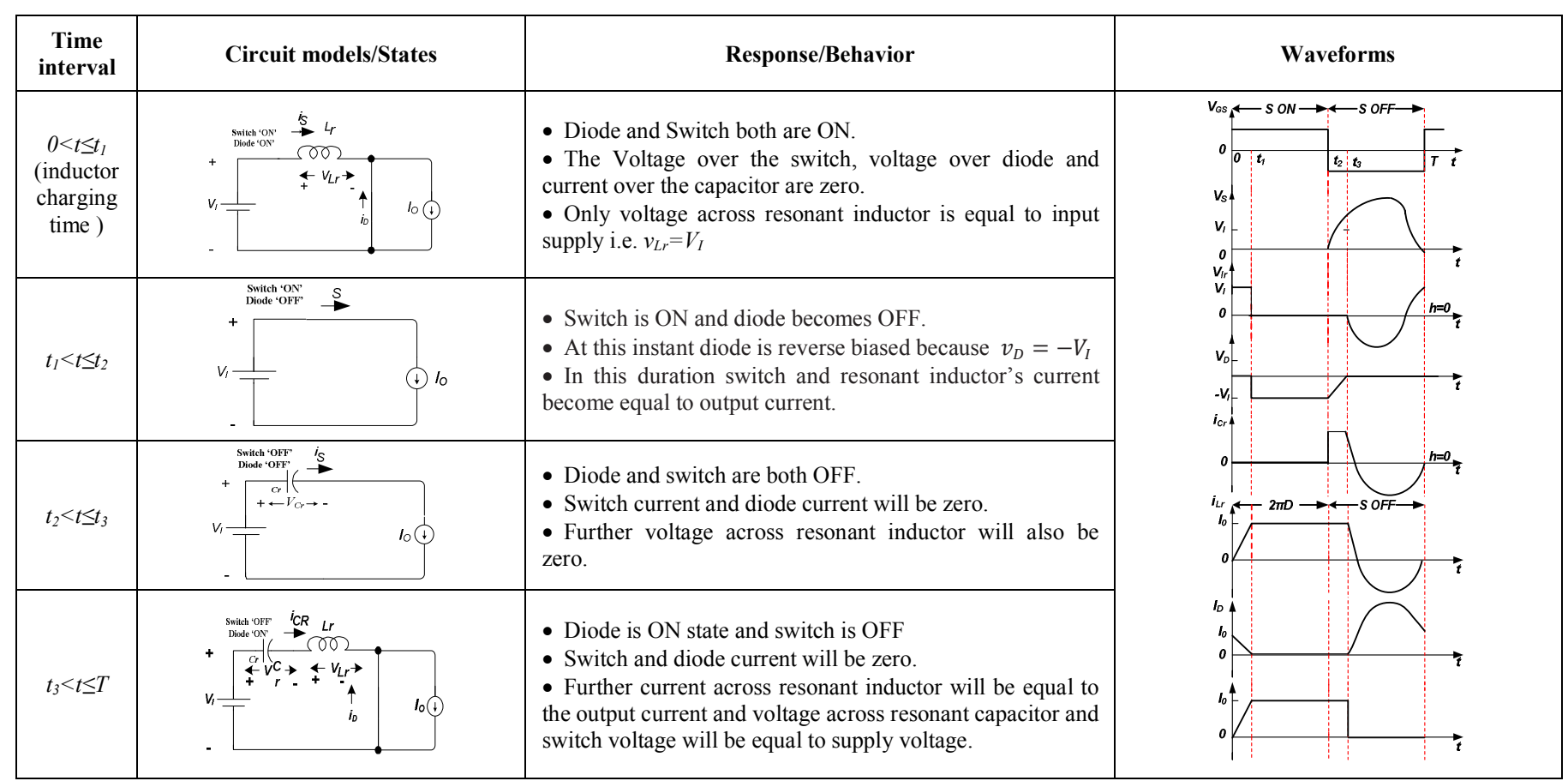

B. With Resonant/Soft-Switch Approach

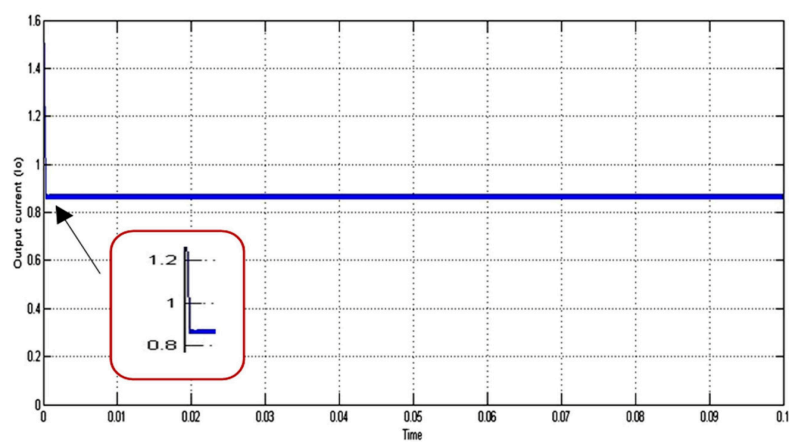

Fig. 12. Output current of buck converter via resonant/soft-switch approach

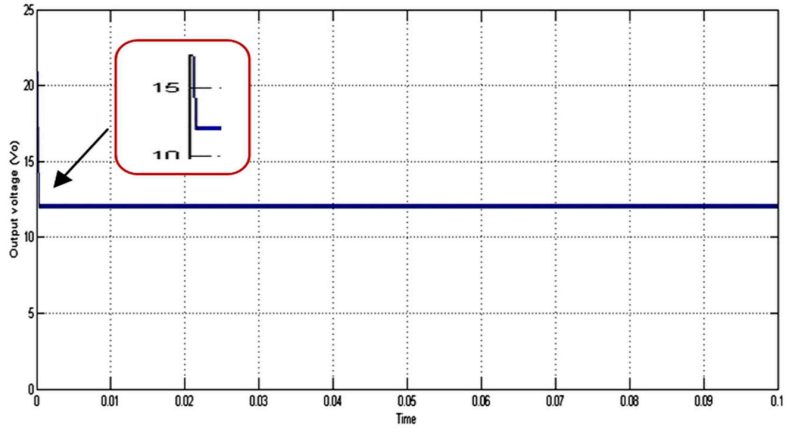

Fig. 13. Output voltage (12V) of buck converter via resonant/soft-switch

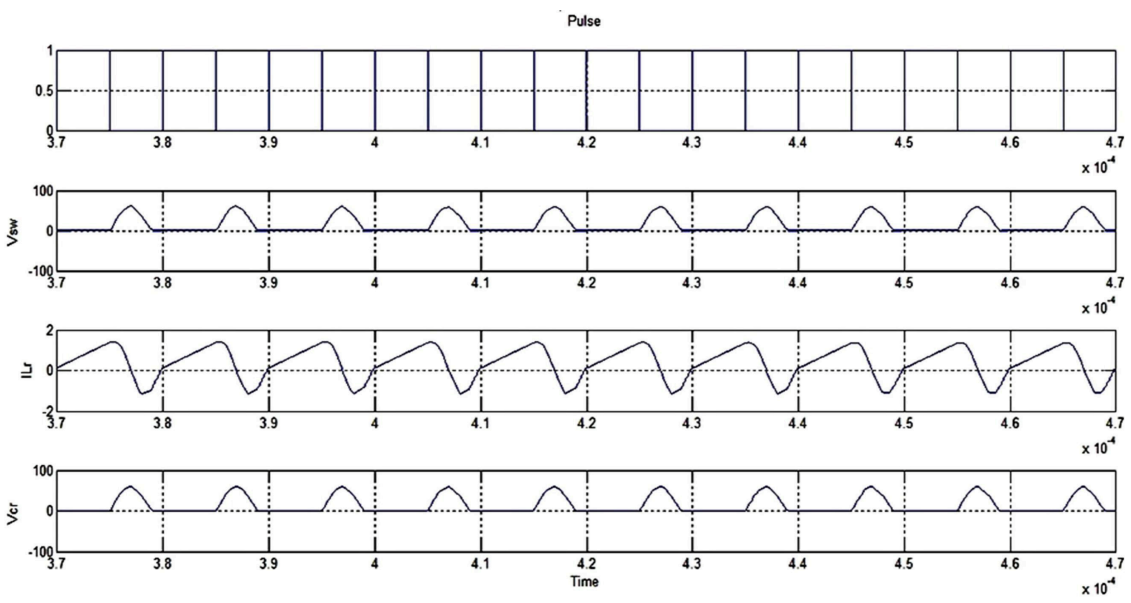

Fig. 14. Outputs of proposed buck converter using resonant/soft-switch approach 


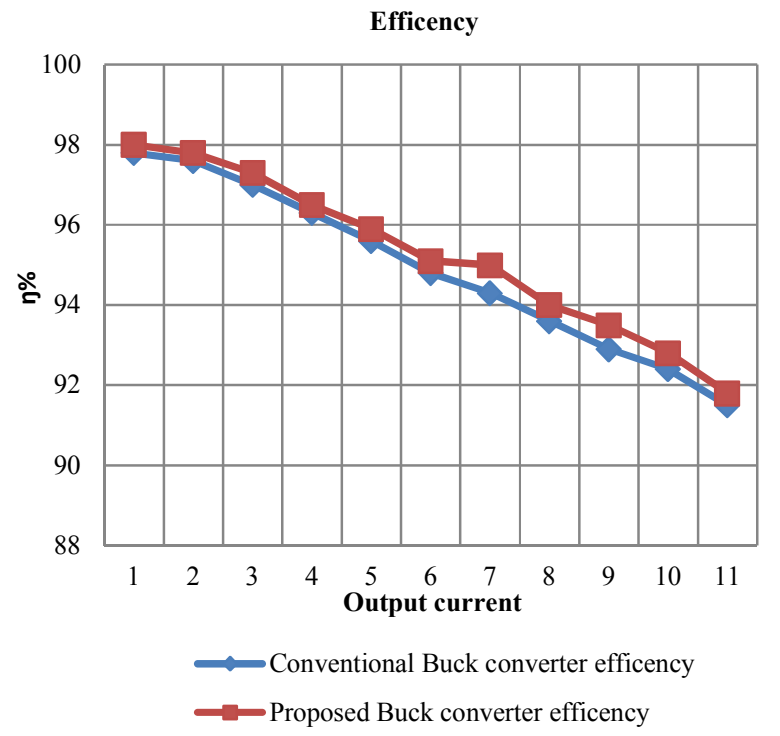

Fig. 15. Plot between efficiency and output current

\section{CONCLUSIONS}

In this paper, analysis has been done for transformer-less dc-dc buck converter topology with and without resonant approach. Pulse width modulating dc-dc converters operate on rigid switching conditions where voltages and currents show their rapid change from high to low value and vice-versa. Because of this, semiconductor devices cause switching loss problems during on and off states which affect the overall system performance. Basically these losses are caused by the capacitance of both diode and transistor. In this research paper, 24-12V transformer-less dc-dc buck converter has been analyzed. Simulation results acquired for the proposed topology justified the soft-switch or resonant approach. This paper shows that if a capacitor is connected in counterpart with switch and a resonant inductor is connected in series with the switch, it absorbs the parasitic elements which provide smooth operation of conversion even on higher switching frequencies. Due to this topology, voltage is zero through the switch during switch-on. That's why, the accumulated energy in output capacitance $C_{o}$ is reduced to zero. Hence, the switching on losses becomes zero, which improves the operational reliability of the dc-dc converter. It has been shown that resonant or zero voltage switch approach makes the buck converter more efficient in comparison to the conventional buck converter. It is also evident that as the current increases, efficiency decreases. So the resonant or soft switch approach plays a crucial role in improving the buck converter efficiency over custom switching buck converter which ultimately improves the performance of the converter.

\section{REFERENCES}

[1] B. W. Williams, "Basic DC-to-DC Converters", IEEE Transactions On Power Electronics, Vol. 23, No. 1, pp. 387-401, 2008

[2] H. A. Huynh, Y. Han, S. Park, J. Hwang, E. Song, S. Kim, "Design and Analysis of the DC - DC Converter With a Frequency Hopping Technique for EMI Reduction", IEEE Transactions on Components,
Packaging and Manufacturing Technology, Vol. 8, No. 4, pp. 546-553, 2018

[3] L. Huber, L. Gang, M. M. Jovanovic, "Design-oriented analysis and performance evaluation of Buck PFC Front End", IEEE Transactions on Power Electronics, Vol. 25, No. 1, pp. 85-94, 2010

[4] V. Vorperian, "Synthesis of medium voltage dc-to-dc converters from low voltage, high-frequency PWM switching converters", IEEE Transactions on Power Electroics. Vol. 22, No. 5, pp. 1619-1635, 2007

[5] M. F. Schlecht, L. F. Casey, "Comparison of the square-wave and Quasi-Resonant Topologies", IEEE Transactions on Power Electronics, Vol. 3, No. 1, pp.83-92, 1988

[6] K. Jayaswal, D. K. Palwalia, G. Jain, P. Kumar, "Design-Oriented Analysis of Non-Isolated DC-DC Buck Converter", Ciencia e Tecnica Vitivinicola Journal, Vol. 30, No. 2, pp. 177-213, 2015

[7] G. Chen, Y. Deng, X. He, Y. Wang, J. Zhang, "Zero-voltage-switching buck converter with low-voltage stress using coupled inductor", IET Power Electronics, Vol. 9, No. 4, pp. 719-727, 2015

[8] N. Mohan, T. M. Undeland, W. P. Robbins, Power Electronics: Converters, Applications, and Design, John Wiley and Sons, 2002

[9] T. W. Ching, K. U. Chan, "Review of Soft-Switching Techniques for High-Frequency Switched-Mode Power Converters", IEEE Vehicle Power and Propulsion Conference, Harbin, China, September 3-5, 2008

[10] K. Shenai, M. Trivedi, P. G. Neudeck, "Characterization of hard- and soft-switching performance of high-voltage Si and 4H-SiC PiN diodes", IEEE Transactions on Electron Devices, Vol. 49, No. 9, pp. 1648-1656, 2002

[11] F. Mihalic, D. Kos, "Conductive EMI Reduction in DC-DC Converters by Using the Randomized PWM", IEEE ISIE, Dubrovnik, Croatia, June 23-25, 2005

[12] C. Y. Chiang, C. L. Chen, "Zero-Voltage-Switching Control for a PWM Buck Converter Under DCM / CCM Boundary", IEEE Transactions on Power Electronics, Vol. 24, No. 9, pp. 2120-2126, 2009

[13] T. F. Wu, S. A. Liang, "A Systematic Approach to Developing SingleStage Soft Switching PWM Converters", IEEE Transactions on Power Electronics Vol. 16, No. 5, pp. 581-593, 2001

[14] B. Lin, H. Chiang, C. Chen, C. Huang, "Implementation of the Soft Switching DC/DC Converter", 2nd IEEE Conference on Industrial Electronics and Applications, Harbin, China, May 23-25, 2007

[15] W. Lee, D. Han, C. Morris, B. Sarlioglu, "Minimizing Switching Losses in High Switching Frequency GaN-based Synchronous Buck Converter with Zero-Voltage Resonant-Transition Switching", 9th International Conference on Power Electronics-ECCE Asia, Seoul, S. Korea, June 15,2015

[16] N. Z. Yahaya, K. M. Begam, M. Awan, "Experimental analysis of a new zero-voltage switching synchronous rectifier buck converter", IET Power Electronics, Vol. 4, No. 7, pp. 793-798, 2010

[17] G. Yanik, E. Isen, "Quasi - Resonant Full - Wave Zero - Current Switching Buck Converter Design , Simulation and Application", Balkan Journal of Electrical \& Computer Engineering, Vol. 1, No. 2, pp. 71-77, 2013

[18] M. Salem, A. Jusoh, N. R. N. Idris, I. Alhamrouni, "Performance Study of Series Resonant Converter Using Zero Voltage Switching", IEEE Conference on Energy Conversion (CENCON), 2014, Johor Bahru, Malaysia, October 13-14, 2014

[19] K. P. Sijin Raj, P. George John, "Buck Converter Using Soft Switching PWM Converter with Current Sharing in Switches", International Journal of Engineering and Innovative Technology, Vol. 2, No. 10, pp. 47-50, 2013

[20] K. H. Liu, F. C. Y. Lee, "Zero-Voltage Switching Technique in DC-DC Converters", IEEE Transactions on Power Electronics, Vol. 5, No. 3, pp. 293-304, 1990 